\title{
Formal and Real Authority in Organizations
}

\section{Citation}

Aghion, Philippe, and Jean Tirole. 1997. Formal and real authority in organizations. Journal of Political Economy 105(1): 1-29.

\section{Published Version}

doi:10.1086/262063

\section{Permanent link}

http://nrs.harvard.edu/urn-3:HUL.InstRepos:4554125

\section{Terms of Use}

This article was downloaded from Harvard University's DASH repository, and is made available under the terms and conditions applicable to Other Posted Material, as set forth at http:// nrs.harvard.edu/urn-3:HUL.InstRepos:dash.current.terms-of-use\#LAA

\section{Share Your Story}

The Harvard community has made this article openly available.

Please share how this access benefits you. Submit a story.

Accessibility 


\title{
Formal and Real Authority in Organizations
}

\section{Philippe Aghion}

University College, London, and European Bank for Reconstruction and Development

\author{
Jean Tirole
}

Institut d'Economie Industrielle, Centre d'Enseignement et de Recherche en Analyse Socioéconomique, and Massachusetts Institute of Technology

This paper develops a theory of the allocation of formal authority (the right to decide) and real authority (the effective control over decisions) within organizations, and it illustrates how a formally integrated structure can accommodate various degrees of "real" integration. Real authority is determined by the structure of information, which in turn depends on the allocation of formal authority. An increase in an agent's real authority promotes initiative but results in a loss of control for the principal. After spelling out (some of) the main determinants of the delegation of formal authority within organizations, the paper examines a number of factors that increase the subordinates' real authority in a formally integrated structure: overload, lenient rules, urgency of decision, reputation, performance measurement, and multiplicity of superiors. Finally, the amount of communication in an organization is shown to depend on the allocation of formal authority.

\section{Introduction}

Over 40 years ago, Herbert Simon defined authority as the right to select actions affecting part or the whole of an organization. ${ }^{1}$ As

We are grateful to Oliver Hart and Martin Hellwig for helpful discussions; to Patrick Bolton, Leonardo Felli, an anonymous referee, and especially Denis Gromb and David Martimort for helpful comments on a first draft; and to the Centre National d'Etudes des Télécommunications for financial support.

1 "We will say that [the boss] exercises authority over [the worker] if [the worker] permits [the boss] to select $x$ [a 'behavior,' i.e., any element of the set of specific actions that the worker performs on the job]. That is, [the worker] accepts authority 
pointed out by Grossman and Hart (1986) and Hart and Moore (1990), authority may be conferred by the ownership of an asset, which gives the owner the right to make decisions concerning the use of this asset. Authority may more generally result from an explicit or implicit contract allocating the right to decide on specified matters to a member or group of members of the organization.

This formal authority, however, need not confer real authority, that is, an effective control over decisions, on its holder. For example, it is commonplace to observe that shareholders have limited control over their board of directors, which itself may be subject to the domination of the top executives, who in turn often rubber-stamp the divisions' projects, and so forth. Similarly, the president of a country really controls only a small number of the decisions made by the executive branch. This paper develops a theory of the allocation of formal authority within organizations and of the separation between formal authority and real authority, thereby showing how a formally integrated structure can accommodate various degrees of "real" integration.

Our approach follows Max Weber's (1968) description of "rational" or "legal" authority. Weber notes that officials, employees, and workers attached to the administrative staff of a bureaucracy do not themselves own the nonhuman means of production and administration, yet they may exert substantial control over the bureaucratic machinery (pp. 217-25). As in Weber, the key to our analysis of formal versus real authority is asymmetric information. A principal who has formal authority over a decision (or activity) can always reverse her subordinate's decision but will refrain from doing so if the subordinate is much better informed and if their objectives are not too antinomic. We formalize this idea in a straightforward way. The subordinate exerts effort (shows initiative) to suggest a project to the principal. The principal also chooses how much to learn about the potential project. Once informed, the subordinate recommends a project that sometimes is not optimal for the principal, because from the point of view of the agent this project creates a higher private benefit, yields better career opportunities, or requires less effort to be implemented than the optimal project. Formal authority prevails when the principal is informed, as she then chooses her preferred project (which may or may not coincide with the subordinate's proposal). In contrast, a poorly informed principal optimally

when his behavior is determined by [the boss's] decision. In general, [the worker] will accept authority only if $x_{0}$, the $x$ chosen by [the boss], is restricted to some given subset ([the worker's] 'area of acceptance') of all the possible values. This is the definition of authority that is most generally employed in modern administrative theory" (Simon 1951, p. 294). See also Jennergren (1981). 
rubber-stamps the subordinate's proposal by fear of picking a worse alternative. The subordinate then has real, although no formal, authority. For instance, a principal who is overloaded with too many activities under her formal authority and therefore has little time to acquire the relevant information on each activity loses effective control and involuntarily endorses many suboptimal projects.

Our analysis suggests two main benefits of delegating formal authority. First, the transfer of formal authority to an agent credibly increases the agent's initiative or incentive to acquire information (which in turn reduces the principal's overload); for such a transfer prevents the principal from overruling the agent in those situations (à la Grossman and Hart [1986]) in which both parties have acquired the relevant information about the potential projects' payoffs. In addition, transferring authority over activities or decisions that matter relatively more to the agent than to the principal and for which the principal's overruling might hurt the agent will facilitate the agent's participation in the contractual relationship. The cost of delegating formal authority is the principal's loss of control over the choice of projects.

Even when the principal retains formal authority, a number of factors tend to generate both initiative and loss of control. One such factor is a wide span of control, which raises the principal's marginal cost of monitoring each agent. We show that there is a sense in which optimal organizations always function in a situation of overload. Alternatively, the gain from the principal's intervention can be reduced by spreading its benefits among several principals/owners; intervention can also be made more difficult by splitting property rights among several superiors (as in the case of a matrix organization or multiministry oversight) and by requiring that intervention be unanimously agreed on. Other factors that increase initiative include the urgency of decision making, which does not give the superior much time for a thorough investigation; repeated interaction, which allows the superior to develop a reputation for not intervening in matters that are relatively inconsequential to her and for intervening only in important matters; and improved performance measurement.

Finally, our approach enables us to provide a modest, but first, step toward the integration of "collective bounded rationality" and incentives and toward the endogenization of the limits of communication. The basic idea is to depart from the traditional team theoretic framework of the literature on communication to allow members to have dissonant objectives. The communication of information is then strategic and depends on the authority relationship. In particular, less communication may take place if the principal has 
formal authority because the agent is concerned that the principal might abuse her authority once she is well informed. This will typically be the case if the principal's and subordinate's objectives are sufficiently dissonant. In the opposite case in which these objectives are sufficiently congruent, we show that communication may instead be encouraged by the agent's subordination to the principal.

Although our analysis is, to the best of our knowledge, new, it makes use of building blocks developed by other authors. The moral hazard and property rights literatures supplied the two polar cases. A seminar given by Diego Rodriguez and Dimitri Vayanos at MIT in 1991 contained several seeds of the basic model described here. ${ }^{2}$ Papers by Riordan (1990), Schmidt (1991), and Crémer (1995) have shown in different contexts that too much information may hurt a principal. ${ }^{3}$ Riordan argues that information allows principals to expropriate the agents' specific investments. He provides a definition of vertical integration based on information. Crémer (in the context of a corporation) and Schmidt (in a paper on privatization) show that poor information allows principals to avoid (ex ante costly) renegotiation of long-term contracts with agents. In Crémer's paper, the principal publicly chooses the accuracy of a technology used to monitor the agent's type. A more accurate technology reduces the agent's incentive to work to signal high ability. Riordan and Schmidt discuss property rights and, in the tradition of Arrow (1975), posit (but do not formally establish) a link between property rights and information structure. So, the observation that too much information can hurt the principal is not novel. Our theoretical contribution is the description of the two-way interaction between authority and information, and the study of when lower layers really have a say in decision making (issue of real authority) and of which tasks are likely to be delegated (issue of formal authority).

The paper is organized as follows: Section II presents the model. Section III identifies the basic trade-off between loss of control and initiative. Section IV analyzes the determinants of the allocation of formal authority within an organization. They include, first, the "relative willingness to pay for authority," which reflects the parties' stakes as well as the congruence of their preferences; second, the principal's information and the importance of the agent's initiative; and, third, the importance of communication between the parties. Section V looks at factors favoring the agent's initiative when the

${ }^{2}$ Their 1993 discussion paper focuses on themes different from the ones considered here.

${ }^{3}$ The literature on the ratchet effect also emphasizes a cost for a principal from being well informed. 
principal has formal authority (overload, urgency of decision, reputation, better performance measurement, and multiple principals), and it derives implications for business management. Section VI summarizes the paper.

\section{The Model}

A hierarchy composed of a principal (she) and an agent (he) can implement one or zero project. The principal hires the agent to collect information about and implement the project. Examples of hierarchies we have in mind are a board of directors/management, chief executive officer/division manager, thesis advisor/student, supervisor/worker, or supranational authority/country.

Projects.-The agent screens among $n \geq 3$ potential and a priori identical projects on behalf of the principal. With each project $k \in$ $\{1, \ldots, n\}$ is associated a verifiable monetary gain or profit $B_{k}$ for the principal and a private benefit $b_{k}$ for the agent. (These payoffs are gross of any monetary transfer between the two parties.) The agent's private benefit includes perks on the job, acquisition of human capital, the possibility of signaling ability, or (minus) the disutility of implementing the project. If no project is implemented, the profit and the private benefit are both equal to zero. "No project" can formally be treated as project 0 , with known payoffs $B_{0}=b_{0}=0$.

For each party, at least one project yields a "sufficiently negative" payoff. In some anticipation, this will imply that an uninformed agent prefers to confess ignorance and to recommend inaction rather than to recommend a specific project, and that similarly an uninformed principal would not choose by herself to undertake a project.

The principal's preferred project yields known profit $B$. Similarly, the agent's preferred project yields known private benefit $b$. If the principal's preferred project is chosen, the agent receives expected private benefit $\beta b$; the expectation refers to the ex ante uninformed situation in which all projects look alike. Similarly, if the agent's preferred project is chosen, the principal receives expected profit $\alpha B$. The congruence parameters $\alpha$ and $\beta$ belong to $(0,1] .{ }^{4}$ If information

\footnotetext{
${ }^{4}$ These congruence parameters will be treated as exogenous in the following analysis. However, one could think of various methods whereby the principal might affect congruence with her subordinates: e.g., investments in the recruiting and training of new employees, design of career profiles, or enforcement of (contractual) rules restricting the subordinates' set of possible actions. Also, the level of congruence might be affected by incentives to implement the project once it is chosen (De Bijl $1994,1995)$. Another interesting determinant of $\alpha$ is the possibility that other agents working for the principal are affected by the activity of this agent. Our focus on private benefits does not preclude the existence of other factors influencing the allocation of authority such as the relative competency of the two parties. Who gets
} 
is hard, we shall further assume that a party's preferred project always yields a positive payoff to the other party (it is trivial to relax this assumption, at the expense of additional notation).

A special case of the payoff structure described above occurs when only two of the $n$ projects are "serious" or "relevant," in that they yield nonnegative profit and benefit whereas the other projects yield negative payoffs. One of the two relevant projects yields profit $B>0$ to the principal and the other zero. Similarly, one of the two relevant projects yields private benefit $b>0$ to the agent, and the other zero. The ex ante probability that the same project is preferred by both is $\alpha=\beta \in(0,1]$, the parameter of congruence.

Preferences. - The principal is risk neutral and has utility $B_{k}-w$ if project $k$ is chosen, and $w$ is the wage paid to the agent. The agent is protected by limited liability, so $w \geq 0$. The agent's utility is then $u(w)+b_{k}$, where $u(\cdot)$ is increasing and concave.

For expositional simplicity we shall assume that the agent is infinitely averse to income risk. He therefore does not respond to monetary incentives and receives a constant wage equal to his reservation wage of zero. Alternatively, the agent may not be infinitely risk averse, but the principal's benefit is noncontractible; the agent's wage is then again a constant. (Section VB shows that the model can be straightforwardly extended to allow the agent to respond to monetary incentives. Profit sharing then lowers the principal's and raises the agent's utility from picking a profitable project.)

Information.-To reflect the nonroutine nature of the decision over which authority may be delegated to the agent, we assume that the nature of projects' payoffs is initially unknown to both the principal and the agent. The agent acquires information in a binary form. At private cost $g_{A}(e)$, he perfectly learns the payoffs of all candidate projects with probability $e$. With probability $1-e$, the agent learns nothing and still views the projects as identical.

Similarly, the principal chooses how much time or effort to devote to learning payoffs. At private cost $g_{P}(E)$, she becomes perfectly informed about the payoffs with probability $E$ and learns nothing with probability $1-E$.

The principal's acquisition of information can be contemporaneous with the agent's or else start after the agent makes his report. We shall refer to these two possibilities as the simultaneous and sequential models, respectively. Which variant is more relevant depends on the context. Sequential investigations usually are less time-consuming

his way may also depend on the bargaining power of the various parties or on the desire of the organization to keep key personnel in the long run (Rotemberg 1993, 1994). 
for the principal, who can already build on an existing report. On the other hand, the principal may not want to wait until the report accrues to start her investigation, since otherwise she may be forced to accept the agent's proposal by lack of time. ${ }^{5}$ Because the simultaneous and sequential cases yield essentially the same results, we shall focus on the simultaneous case and content ourselves with illustrating the sequential case in Section $\mathrm{VE}$. We leave the endogenization of the timing (simultaneous vs. sequential) for future research.

The disutilities of effort $g_{A}(\cdot)$ and $g_{P}(\cdot)$ are increasing and strictly convex and satisfy $g_{i}(0)=0, g_{i}^{\prime}(0)=0$, and $g_{i}^{\prime}(1)=\infty, i=A, P$.

Communication.-In most of the paper we can assume that information is either hard or soft. Hard information about a project's payoffs can be costlessly and instantaneously verified by the other party if communicated by the party who collected it. Soft information cannot be verified by the other party, and therefore its communication must be interpreted as a pure suggestion for a project choice. The specific results of Section VE rely on the existence of soft information.

Authority. - In the case of $P$-formal authority (which we shall occasionally label "integration"), the principal has the formal authority and is called the "superior." The principal may always overrule the agent (the "subordinate"). She indeed does so if she is informed and if the agent's recommendation is not "congruent." In this case, the principal has both the formal and real authority over the choice of project and can fully dispense with the agent's information and recommendation. Otherwise, she (optimally) rubber-stamps the agent's proposal since $\alpha>0$. We shall then say that the agent has real authority.

Our payoff structure implies that there is no need to include an "exit option" for the subordinate, for the superior always makes a decision that yields nonnegative expected utility to both. The standard institution of letting subordinates quit if they are unhappy with their superiors' decisions emerges naturally in the variant of our model in which the principal's preferred project may impose a substantial loss of utility for the agent.

Under A-formal authority (which we shall also label "delegation"), the "independent agent," if informed, picks his preferred project and cannot be overruled by the principal. That is, the agent now has formal authority. Note that this covers the situation in which the agent is an employee who contractually receives an irrevocable

\footnotetext{
${ }^{5}$ For instance, directors of a company or external members of a thesis jury are usually forced to rubber-stamp the annual report or to accept the thesis if they have waited until receiving the documents to become involved.
} 
right to make this particular decision. Indeed, there is in general not one but many decisions to be picked in an organization. Accordingly, a given organization may admit many intermediate allocations of formal (and not only real) authority between a fully integrated organization, in which the principal has formal authority over all decisions, and a fully disintegrated organization. A contract, a corporate charter, customs, and the law may endow the agent with the right to make specific decisions, leaving the principal in charge of the remaining ones. For example, the directors of a corporation, who are agents for (in particular) the shareholders, have wide powers, with shareholders having formal authority only in specific issues (fundamental changes such as a change in corporate charter or a merger, decisions on which directors have conflicts of interest, or election of directors). Within corporations, there has been de facto a recent trend in management toward "empowerment" and "teamwork," which by and large amount to a reassignment of some decision rights to lower tiers of the hierarchy. ${ }^{6}$

Contracts. - We adopt an incomplete contracting approach (Grossman and Hart 1986) by positing that projects cannot be described and contracted on ex ante. The initial contract specifies an allocation of formal authority (control rights) to only one of the two parties.

The timing is as follows: (i) The principal proposes a contract that allocates formal authority to her or to the agent over the future choice of projects; ${ }^{7}$ (ii) the parties privately gather information about the $n$ projects' payoffs; (iii) the party who does not have formal authority communicates to the controlling party a subset (of his choice) of the relevant projects' payoffs he has learned; and (iv) the controlling party picks a project (or none) on the basis of his information and the information communicated by the other party.

Payoffs under the two allocations of authority.-Under P-formal authority (integration), the utilities are

$$
u_{P}=E B+(1-E) e \alpha B-g_{P}(E)
$$

and

${ }^{6}$ Anecdotal evidence on the delegation of formal authority within organizations is contained in the celebrated work by Chandler (1962) on Strategy and Structure. This work provides a detailed description of how large companies such as Du Pont, General Motors, and Standard Oil, after having greatly expanded the scope of their production activities, decided to change their organizational mode toward a more decentralized structure.

${ }^{7}$ That is, we assume that there is, ex ante, a competitive supply of potential agents, so that the allocation of authority between the two parties is the one that maximizes the principal's ex ante expected utility. 


$$
u_{A}=E \beta b+(1-E) e b-g_{A}(e) .
$$

That is, with probability $E$, the principal is informed and picks her preferred project. With probability $1-E$, the principal is uninformed. With probability $e$, the agent is informed and suggests his preferred project. The principal then either learns from his recommendation her payoff attached to this project (hard information) or is still uncertain about whether the agent proposes her preferred project (soft information). Either way, the principal optimally rubber-stamps the agent's proposal. ${ }^{8}$

Under $A$-formal authority (delegation) when informed, the agent simply chooses his preferred project. When the agent is uninformed and the principal is informed, the principal suggests her preferred project, which is then implemented by the agent. So, with the superscript $d$ for "delegation," preferences are

$$
u_{P}^{d}=e \alpha B+(1-e) E B-g_{P}(E)
$$

and

$$
u_{A}^{d}=e b+(1-e) E \beta b-g_{A}(e) .
$$

Note that the agent's lack of responsiveness to monetary incentives precludes any ex post renegotiation of the exercise of authority.

Remark on complete contracts.-To put the incomplete contracting approach somewhat in perspective, our discussion paper (Aghion and Tirole 1994) explored the polar assumption that projects can be described and contracted on ex ante, even though their payoffs are ex ante unknown to both parties. It is interesting that under weak assumptions, the optimal complete contract corresponds exactly to a possibly random authority allocation scheme as long as the agent does not respond to monetary incentives. (See Tirole [1994] for a further discussion of when an incomplete contract approach to authority yields the same outcome as the complete contract, unknown payoffs approach.)

${ }^{8}$ That the principal's formal authority becomes entirely ineffective when the principal is uninformed follows from the specific payoff structure, in particular from the principal's weakly preferring a (relevant) noncongruent project to no project at all. To see this, consider the following example: there are three "relevant" projects (thus $n \geq 4$ ), say $k=1,2$, and 3 (the principal does not know that the relevant projects are projects $1-3$ ). Project 3 yields a strictly negative profit to the principal, whereas projects 1 and 2 yield (as above) a nonnegative profit. Then, if information is hard, the principal, whenever uninformed, can still use her formal authority in order to elicit information about project 3 vs. projects $\{1,2\}$ from the agent. The principal will then rubber-stamp the agent's decision only if information ruling out the negative-profit project has been disclosed to her. 


\section{The Basic Trade-off between Loss of Control and Initiative}

Consider the case in which the principal has formal authority. The reaction curves in information gathering for the principal and the agent are defined by the first-order conditions

$$
(1-\alpha e) B=g_{P}^{\prime}(E)
$$

and

$$
(1-E) b=g_{A}^{\prime}(e) \text {. }
$$

The principal supervises more, the higher her stake and the lower the congruence parameter $\alpha$ and the agent's effort. The agent demonstrates more initiative, the higher his private benefit and the lower the principal's interference.

We assume that the two systems of equations $\{(5),(6)\}$ have a unique, stable intersection $(E, e) \cdot{ }^{9}$ (Such an assumption is not needed in the sequential case: Because the principal acquires information only if the agent makes a proposal, $E$ is independent of $e$ and the stability condition is automatically satisfied. $)^{10}$

The fact that the agent's reaction curve (6) is downward sloping is a crucial feature of this (or any) initiative model. In contrast, if the agent's reaction curve were upward sloping, the principal would never want to reduce her degree of interference $E$ for strategic reasons. This latter case might correspond either to a situation of strategic complementarity if the principal's reaction curve were also upward sloping or to a supervision situation if the principal's reaction curve were downward sloping. (A well-known example in which the agent's reaction curve is upward sloping is the monitoring model. In contrast to our model, in monitoring [or costly state verification] models, what constitutes a wrong action is known in advance to both parties: engage in strategic default [borrower], cheat the Internal Revenue Service [taxpayer], embezzle corporate resources [manager], etc. In a monitoring model, an increase in the principal's effort to measure or verify ex post the agent's performance will unambiguously induce the agent to behave better. In our model, an increase in the principal's effort worsens performance measurement by lowering the impact of the agent's action on outcome, and thus reduces the agent's effort.)

\footnotetext{
${ }^{9}$ That is, $\alpha b B<g_{P}^{\prime \prime}(E) g_{A}^{\prime \prime}(e)$. is

${ }^{10}$ For example, with soft information, the principal's payoff in the sequential case

$$
u_{P}=e\left[E B+(1-E) \alpha B-g_{P}(E)\right] .
$$
}


Suppose now that for some "exogenous" reason (e.g., because of overload), the marginal cost of effort of the principal (i.e., $g_{P}^{\prime}$ ) increases. The effect on the principal's expected payoff is a priori ambiguous. On the one hand, ceteris paribus, the principal's probability of becoming informed about the projects' payoffs $(E)$ decreases (see eq. [5]); the principal thus loses real authority (i.e., control) over the choice of project, with a higher resulting risk of having to endorse suboptimal projects. On the other hand, the reduction in the principal's intervention $E$ encourages initiative from the subordinate (see eq. [6]), which in turn raises the principal's expected (monetary) benefit.

\section{The Optimal Allocation of Formal Authority}

When should formal authority be allocated to the principal and when should it instead be delegated to the agent? In the following subsections we identify some determinants of the allocation of formal authority in organizations. Both incentive (initiative) and individual rationality (participation) considerations appear to be relevant, although the two corresponding approaches to delegation have different and complementary testable implications: see subsection $C$ below.

\section{A. The Incentive View of Delegation}

Both the delegation of formal responsibility described by Chandler (1962) in his study of Du Pont and General Motors and the recent move toward empowerment and teamwork were officially motivated by the need to increase initiative at lower layers of the hierarchy.

In terms of our model, when formal authority is delegated to the agent, the reaction curves of the principal and the agent become, respectively,

$$
(1-e) B=g_{P}^{\prime}(E)
$$

and

$$
(1-\beta E) b=g_{A}^{\prime}(e) .
$$

Assuming again that $\{(7),(8)\}$ yields a unique, stable equilibrium $\left(E^{d}, e^{d}\right),{ }^{11}$ one can show that $E>E^{d}$ and $e<e^{d}$. Delegation thus increases the agent's initiative; because the principal cannot over-

\footnotetext{
${ }^{11}$ The stability condition is the same as in the case of $P$-formal authority, except that $\alpha$ is replaced by $\beta$.
} 
rule the agent, the agent has more incentives to become informed. ${ }^{12}$ The cost of leaving initiative to the agent, on the other hand, is again a loss of control (both formal and real since the principal has less incentive to become informed when she delegates formal authority to the agent). ${ }^{13}$

Remark.-The result that delegated projects require less attention has implications for the choice of activities under alternative authority structures. The monetary rates of return take no account of the activity's use of an unpriced scarce corporate resource, namely the principal's time and attention. Therefore, internal activities should receive a handicap relative to external ones. In particular, in a situation in which corporate headquarters must decide which activities should be pursued internally and which should be delegated, the former should face a higher hurdle rate than the latter since they make more use of the headquarters' time.

\section{B. The Participation View of Delegation}

Our basic model emphasizes the role of delegation in fostering incentives. In practice, delegation of formal authority also plays a role in ensuring the agent's participation. For example, the delegation to the agent of choices relative to clothing, hairdo, out-of-work lifestyle, or other personal matters often has minor incentive effects and substantial importance for the agent. The direct determinants of the allocation of formal authority are obtained by focusing on individual rationality and setting aside effort elasticity considerations.

Delegating a choice to the agent raises his utility and enables the

${ }^{12}$ A referee wondered about the possible negative effect of delegation on incentives: Suppose that there exists an $(n+1)$ th project $A$, which, without the agent's having to investigate, is known to yield a positive payoff $b_{A}>\beta b$ to the agent and a negative payoff $B_{A}<0$ to the principal. Then, one can show that delegating formal authority to the agent may result in a reduction of the agent's effort (i.e., $e>e^{d}$ )! Indeed, while $e$ remains determined by the first-order condition (6), now the agent's effort $e^{d}$ when formal authority is delegated to him solves the maximization program

$$
\max \left\{e b+(1-e) b_{A}-g_{A}(e)\right\}
$$

i.e., $e^{d}$ satisfies the new first-order condition

$$
b-b_{A}=g_{A}^{\prime}\left(e^{d}\right),
$$

which in turn yields $e^{d}<e$ when $b_{A}>\beta b$ and $E$ is sufficiently small. This, however, does not invalidate our analysis in this section. For the optimal contract will always involve either ruling out project $A$ (which yields a negative payoff to the principal) a priori if $A$ 's payoffs are known ex ante to both parties or introducing contingent veto powers (as in Tirole [1994]) if $A$ 's payoffs are learned only ex post. In either case, we obtain again that $e^{d}>e$.

${ }^{13}$ Our model thus explains why the absence of integration (where "integration" is understood as $P$-formal authority) corresponds, as is often suggested in the literature (e.g., in Williamson [1975, 1985]), to an arm's-length relationship. 
principal either to lower the wage or to recoup authority on another decision, while keeping the agent's individual rationality constraint satisfied. We delay the study of monetary incentives until Section V and here focus on a multitask version of the basic model. Suppose that there are $m$ independent decisions, $k=1, \ldots, m$. Each decision $k$ is characterized by profit $B_{k}$, private benefit $b_{k}$, congruence parameters $\alpha_{k}$ and $\beta_{k}$, and efforts $E_{k}$ and $e_{k}$. To isolate the direct effects, we ignore the incentive constraints and take $E_{k}$ and $e_{k}$ as given. Let $x_{k}$ $=1$ if the principal keeps control of decision $k$ and $x_{k}=0$ if the decision is delegated. The optimal delegation pattern maximizes the principal's payoff subject to the agent's participation constraint:

$$
\max _{\{x\}} \sum_{k}\left\{\left[E_{k}+\left(1-E_{k}\right) e_{k} \alpha_{k}\right] x_{k}+\left[e_{k} \alpha_{k}+\left(1-e_{k}\right) E_{k}\right]\left(1-x_{k}\right)\right\} B_{k}
$$

subject to

$$
\begin{aligned}
\sum_{k}\{ & {\left[E_{k} \beta_{k}+\left(1-E_{k}\right) e_{k}\right] x_{k} } \\
& \left.+\left[e_{k}+\left(1-e_{k}\right) E_{k} \beta_{k}\right]\left(1-x_{k}\right)\right\} b_{k} \geq \bar{u} .
\end{aligned}
$$

Letting $\mu$ denote the multiplier of the participation constraint, we obtain the following intuitive result:

$$
\begin{aligned}
\frac{b_{k}\left(1-\beta_{k}\right)}{B_{k}\left(1-\alpha_{k}\right)} & <\frac{1}{\mu} \Rightarrow x_{k}=1 \\
& >\frac{1}{\mu} \Rightarrow x_{k}=0 .
\end{aligned}
$$

In the absence of incentive considerations, delegation decisions are driven by the relative willingness to pay for authority. Ceteris paribus, delegation is more likely for those decisions that matter little to the principal, either because they involve little cash flow $\left(B_{k}\right.$ low) or because the agent can be trusted ( $\alpha_{k}$ high), and that are important to the agent, either because private benefits are high $\left(b_{k}\right.$ high) or because the principal cannot refrain from hurting the agent $\left(\beta_{k}\right.$ low).

It is interesting to note that the allocation of formal authority defined by (9) is independent of efforts. Authority on a decision makes a difference only when both parties are informed about the consequences of the decision. The cost and benefit of delegating authority on decision $k$ are both proportional to the probability $E_{k} e_{k}$ that information is shared. By contrast, effort considerations are crucial for the incentive effects of the allocation of authority. 


\section{Delegation of Authority: Testable Implications}

The "incentive view" (subsection $A$ ) and the "participation view" (subsection $B$ ) yield complementary determinants of the allocation of formal authority. We analyze their testable implications in sequence. We indicate why we think these implications are realistic, although only more thorough studies based on the structural model can deliver conclusive evidence.

\section{Relative Willingness to Pay for Authority}

Participation considerations lead to an allocation of formal authority on decisions $k=1, \ldots, n$ based on the relative willingness to pay $B_{k}\left(1-\alpha_{k}\right) / b_{k}\left(1-\beta_{k}\right)$ of the two parties. From this, we have derived the following simple implications: $(a)$ Only decisions that are relatively unimportant for the principal $\left(B_{k} / b_{k}\right.$ low) should be delegated, as has been documented in the organizational design literature. ${ }^{14}$ (b) Decisions for which the principal cannot trust the agent $\left(\alpha_{k}\right.$ low) or for which the agent can trust the principal ( $\beta_{k}$ high) should not be delegated. These congruence effects seem to fit with empirical evidence on authority conferred on corporate divisions. A division manager's preferred decisions are likely to be very suboptimal for the firm $\left(\alpha_{k}\right.$ low) when there are substantial externalities on other divisions, on future managers of the division, or on the firm as a whole. And, traditionally, long-term investment decisions or decisions having an impact on the rest of the firm's image or strategy (such as advertising or bargaining with unions) have been kept centralized. By contrast, managerial decisions concerning almost exclusively the division at present, such as manufacturing, purchasing, or short-term investment, are very often delegated to the division.

Similarly, our conclusion that the likelihood of delegation decreases with the congruence parameter $\beta_{k}$ seems consistent with casual observation. Employees are willing to relinquish authority to managers they trust. Conversely, contracts or the law should prevent employees against having to comply with orders to implement policies they find offensive (such as covering up a scandal, polluting a river, etc.).

\section{Initiative as a Determinant of Delegation}

Viewed from the incentive perspective, the impact of payoff and congruence parameters is less clear-cut. Consider, for example, an in-

\footnotetext{
${ }^{14}$ Facts on which decisions are delegated can be found, e.g., in Jennergren (1981). Incidentally, the definitions of formal and real authority used in the organizational design literature correspond to ours.
} 
crease in the principal's profit $B_{k}$. On the one hand, the decision is more important for the principal, which increases the cost of the loss in control associated with delegation. On the other hand, the increase in $B_{k}$ leads to more monitoring and further stifling of initiative. One parameter, though, yields an unambiguous prediction. As with the participation view, an increase in the agent's trust in the principal $\left(\beta_{k}\right)$ makes centralization more desirable: This increase has no impact on the principal's payoff under centralization and reduces the agent's effort under delegation.

The incentive view may be the key to understanding delegation decisions that respond to changes in information acquisition. (Recall from subsection $B$ that the participation view does not assign a direct role for information acquisition in explaining authority patterns.) We already noted that the delegation of responsibility to divisions and the move toward empowerment are usually motivated by initiative considerations. To provide a further illustration, suppose that the principal's probability of being informed on a given issue is exogenous, since it stems from public information or the principal's past experience rather than from a current search by the principal. A quick inspection of equation (3) shows that the principal should retain authority when she is very well informed $\left(E_{k} \text { high }\right)^{15}$ since initiative becomes a minor consideration. For example, one would predict that the principal would keep decision rights for those activities that she knows very well from experience, namely the "core competencies." 16

\section{Intermediate Allocations of Formal Authority}

Our analysis so far has concentrated on the benefits and costs of the full delegation of formal authority over a decision or set of decisions. In practice, however, one commonly observes "intermediate" patterns of delegation, with decision rights being delegated "conditionally" or to a third party (middleman) with intermediate objectives between the principal's and the agent's.

\section{Contingent Delegation}

Sometimes a principal delegates authority to an agent but keeps the possibility of reestablishing authority at the expense of a high cost

\footnotetext{
${ }^{15}$ If $E_{k} \geq \alpha_{k}$, under delegation the principal prefers the agent to be uninformed. Hence, she might as well keep the decision right.

${ }^{16}$ Similarly, we would predict that, when a change in a division is desirable, the decision is more likely to be decentralized if the change is "innovative" rather than "imitative" (since, for imitative changes, the principal obtains substantial information from the experience of other firms or other units). There is some evidence, although weak, in this direction (Jennergren 1981).
} 
of intervention. For example, the agent does not need prior approval to make a decision and to get an activity going, whereas the principal may engage in an ex post evaluation and stop operations. Overruling the agent is then quite costly and occurs only if the principal discovers that the loss from noncongruence is substantial. One can then speak of "contingent delegation" in that the principal does not always overrule the agent when he learns that some other course of events would have been more profitable. The formalization of this idea involves a straightforward extension of our analysis: Suppose that there are two relevant projects and that $B$ is ex ante random instead of deterministic: $B$ is equal to $\underline{B}$ or $\bar{B}$, where $0<\underline{B}<\bar{B}$. Suppose that reversing a project $\operatorname{costs} c \in(\underline{B}, \bar{B})$ once the project is started. We can now compare three allocations of authority: two allocations, $P$-formal authority or no delegation (the agent needs prior approval) and $A$-formal authority or full delegation (the principal cannot overrule the agent), are as described in the previous sections (with $B$ now denoting the expectation of the highest profit). The third and new allocation of authority is the case of "contingent delegation" or "ex post validation." In the example above, the principal ex post rubber-stamps whenever the highest profit is $\underline{B}$ and overrules when this profit is $\bar{B}$.

Contingent delegation is intermediate between delegation and no delegation in terms of initiative and loss of control. Applications of the idea of contingent delegation are not limited to the internal organization of firms. In politics, authority over certain decisions is delegated to a president but may be taken away from her at the cost of an impeachment procedure. In corporate finance, a board of directors or a management team may lose control after a takeover or a proxy fight. (Note that the cost $c$ of regaining delegated authority may or may not be a pure deadweight loss. For example, it may represent a golden parachute or a takeover premium.)

\section{Delegation to an Intermediary}

It is sometimes the case that decisions affecting agents (including difficult ones such as restructuring a company, laying off workers, imposing discipline, etc.) are being delegated by company owners to managers. One explanation for this (which again can be formalized using a straightforward extension of our model) may simply be that by delegating decision rights to managers or supervisors with intermediate (in terms of congruence) objectives between hers and her agents', the principal commits herself to limiting the expected cost for the agents of being deprived of formal decision rights. This, in turn, enables the principal to encourage the agents' participation 
and initiative while at the same time limiting the expected cost of her losing formal authority and thus direct control over decisions.

\section{E. Authority and Communication}

This subsection extends the basic framework by introducing the possibility that the agent communicates some prior information he may privately hold about the projects. A natural question then is whether the allocation of formal authority affects the communication of (relevant) information by the agent.

We assume that at the beginning the agent can communicate information that reduces the principal's marginal cost of investigation from $g_{P}^{\prime}$ to $\tilde{g}_{P}^{\prime}$ such that $g_{P}^{\prime}(E)>\tilde{g}_{P}^{\prime}(E)$ for all $E>0$. (For example, the agent might privately know that the relevant projects belong to a subset $N_{1}$ of $N$ and decide whether to reveal $N_{1}$ to the principal.) The action of communicating information to the principal is noncontractible. The timing is as described in Section II except that the agent chooses whether to communicate his private information to the principal after the allocation of the decision right. Then the two parties choose noncooperatively how much effort ( $E$ and $e$ ) to invest in learning the projects' payoffs. Depending on the allocation of formal authority, the equilibrium efforts are given by the first-order conditions $(5)-(8)$ for the relevant marginal disutility of effort function for the principal $\left(g_{P}^{\prime}(\cdot)\right.$ or $\left.\tilde{g}_{P}^{\prime}(\cdot)\right)$.

Communication shifts the principal's reaction curve up (regardless of the allocation of formal authority) and has no effect on the agent's reaction curve. The principal's monitoring effort $E$ thus increases in a stable equilibrium. The question of whether the agent wants to communicate information to the principal thus boils down to whether the agent gains from the principal's being better informed. Without loss of generality, let us index the principal's marginal disutility function by a communication parameter $K \in[0,1]$, $h_{P}^{\prime}(E, K)$ with $h_{P}^{\prime}(E, 0)=g_{P}^{\prime}(E)$ and $h_{P}^{\prime}(E, 1)=\tilde{g}_{P}^{\prime}(E)$ for all $E$ and $h_{P}^{\prime}(E, K)$ decreasing in $K$. We just noted that the principal's equilibrium efforts $E(K)$ and $E^{d}(K)$ increase with $K$. From the envelope theorem, the impact of communication on the agent's utility (see eqq. [2] and [4]) is given by

$$
\frac{d u_{A}}{d K}=(\beta-e) b \frac{d E}{d K}
$$

and

$$
\frac{d u_{A}^{d}}{d K}=\left(1-e^{d}\right) \beta b \frac{d E^{d}}{d K}
$$


An independent agent always benefits from the principal's being better informed. ${ }^{17}$ In contrast, a subordinate wants to communicate information if his expected gain from the superior's becoming informed, $\beta b$, exceeds the expected benefit from having real authority, $e b$, or $\beta>e$. When the congruence parameter $\beta$ is low, $\beta<e,^{18}$ so the agent is better off not communicating his information. In case of low congruence, there is more communication by an independent agent.

In this framework, there is actually always at least as much communication under $A$-formal authority. This may no longer be the case if congruence is high and the agent incurs a direct (fixed) cost of communicating the information, as can be seen from equation (10). The agent no longer derives a benefit from the principal's being ex ante well informed if he himself is well informed ( $e^{d}$ close to one). If the agent's private benefit is high enough so that $e^{d}$ is indeed close to one, the independent agent does not bother incurring the cost of communicating ex ante information. In contrast, it may be the case (this can be checked with quadratic payoffs) that, provided that congruence is high enough,

$$
\frac{d u_{A}}{d K}>\frac{d u_{A}^{d}}{d K} \simeq 0
$$

In summary, the allocation of formal authority affects the agent's incentives to communicate prior information to the principal. The impact of the allocation of formal authority on communication depends on the parameters of the model, in particular the degree of congruence between the principal's and the agent's objectives. More communication may take place under $P$-formal authority if these objectives are sufficiently congruent; less communication will take place if they are too dissonant.

\section{Factors Favoring Initiative When the Principal Has Formal Authority}

In this section, we assume that full delegation of formal authority is dominated, ${ }^{19}$ and we explore a few determinants of the agent's real

${ }^{17}$ That communication can never be detrimental to an independent agent is unlikely to be robust to various extensions of our basic model, in particular, to the introduction of the agent's responsiveness to monetary incentives. For example, one could imagine that an independent agent might prefer not to help the principal find out that the two parties' preferences are congruent in order to credibly blackmail the principal ex post and thereby obtain a higher monetary compensation.

${ }^{18}$ One has $\lim _{\alpha \rightarrow 0} e=g_{A}^{\prime-1}\left[\left[1-g_{P}^{\prime-1}(B)\right] b\right]>0$, and $e$ as defined by (5) and (6) is increasing in $\alpha$. Thus $e$ remains uniformly bounded away from zero as $\alpha$ varies.

${ }^{19}$ For example, there might be states of nature in which the agent could impose very bad decisions for the principal (i.e., in which $\alpha$ is very negative) if formal authority were delegated to him. 
authority under centralization by extending the basic model in a few simple directions.

\section{A. Span of Control, Overload, and Initiative}

It is often argued that the planning and allocation process of the large conglomerates that were formed in the 1960s became bureaucratized and that the headquarters were responsible for too many units, whose strategy they could not understand or influence. This called for a refocus on "core businesses." The purpose of this subsection is to introduce the superior's span of control and overload into the analysis. Suppose that a superior has authority over $m$ identical subordinates. Each subordinate $i$ screens in a set of tasks as described in Section II and learns the corresponding payoff structure with probability $e_{i}$. The principal's disutility of efforts is $g_{P}\left(\sum_{i} E_{i}\right)$, where $E_{i}$ is the principal's probability of learning the payoffs of agent $i$ 's activity. The subordinates' tasks are independent. There is a fixed cost $f$ per subordinate. ${ }^{20}$ So, the principal's payoff is

$$
u_{P}=\sum_{i}\left[E_{i} B+\left(1-E_{i}\right) e_{i} \alpha B-f\right]-g_{P}\left(\sum_{i} E_{i}\right) .
$$

Each agent's reaction curve is still given by

$$
\left(1-E_{i}\right) b=g_{A}^{\prime}\left(e_{i}\right) \text {. }
$$

We assume that the equilibrium is symmetric ${ }^{21}$ and stable:

$$
\begin{gathered}
(1-\alpha e) B=g_{P}^{\prime}(m E), \\
(1-E) b=g_{A}^{\prime}(e) .
\end{gathered}
$$

Let $\{E(m), e(m)\}$ denote the solution to the system of equations $\{(15),(16)\}$. Abusing notation, let

$$
u_{P}(m) \equiv m R(E(m), e(m))-g_{P}(m E(m)),
$$

where

$$
R(E(m), e(m)) \equiv E(m) B+[1-E(m)] e(m) \alpha B-f
$$

is the revenue per subordinate. When the envelope theorem is used and $m$ is treated as a real number, the optimal span of control is

${ }^{20}$ The superior would choose to have an infinite number of subordinates in the absence of a fixed cost (or, equivalently, of a positive reservation wage of the subordinates). A finite size is obtained when $f>\left[g_{A}^{\prime-1}(b)\right] \alpha B$.

${ }^{21}$ There also exist asymmetric equilibria in which the principal devotes all her attention to a subset of agents, who therefore lack initiative, and none to the others. To eliminate asymmetric equilibria, one can assume that the probabilities $\left\{E_{i}\right\}$ are sufficiently nonsubstitutable in the principal's disutility of effort function. 
obtained from

$$
\frac{d u_{P}}{d m}=\left[R(E(m), e(m))-E(m) g_{P}^{\prime}(m E(m))\right]+m \frac{\partial R}{\partial e} \frac{d e}{d m}=0 .
$$

The expression in brackets in (17) is the marginal profit associated with a unit increase in the span of control. An extra agent brings revenue $R$ but requires attention $E$, which raises the cost of supervision by $E g_{P}^{\prime}$, the "overload cost." The second term, in $(\partial R / \partial e)$ $\times(d e / d m)>0$, is the "initiative effect" and measures the increase in the agent's effort associated with a reduction in oversight.

We shall say that a firm is in a situation of overload if the marginal profit of an extra employee, with employee behavior held constant, is negative. Equation (17) shows that it is always optimal for the firm to be in a situation of overload so as to credibly commit to rewarding initiative. ${ }^{22}$

Remark.-The analysis in this subsection has an interesting dynamic application: Suppose that the implementation of projects takes place continuously over time and that at each point in time the principal can freely adjust the span of control by hiring or firing subordinates. Assume furthermore that the principal acquires experience about her subordinates as time passes by (there is learning by doing in monitoring). Then the trade-off between overload costs and initiative has the following dynamic equivalent: Letting the firm grow fast (i.e., hiring new subordinates at a high speed) involves high overload costs and therefore a loss of control for the principal; on the other hand, a slow-growth policy is more likely to stifle the subordinates' initiative as the principal acquires experience on monitoring them.

\section{B. Performance Measurement and Subordinates' Responsiveness to Monetary Incentives}

The economics literature has emphasized the effect of the allocation of control on incentives. This subsection shows that incentives feed back on control. To this purpose, we generalize our theory to allow the agent to respond to monetary incentives. The profit is verifiable, and the agent's utility for project $k$ is $u(w)+b_{k}$ (where $u(0)=0$,

\footnotetext{
${ }^{22}$ Because the marginal profit is negative, the principal would be better off committing herself, say, to playing golf rather than reaching overload. The problem with this is that playing golf is not a credible commitment (recall that the $g_{P}(\cdot)$ function summarizes the principal's disutility of supervision and therefore already includes the cost of forgone opportunities). Overload is a credible commitment not to stifle initiative.
} 
$u^{\prime}>0$, and $u^{\prime \prime}<0$ ). We assume for simplicity that there are two relevant projects, with profits $B$ and zero, respectively, which implies that $\alpha=\beta$. Without loss of generality, the agent receives $w \geq 0$ when the principal's profit is $B$, and zero otherwise.

The principal's net profit in her preferred project is now $\tilde{B} \equiv$ $B-w$. The agent's average gain from being informed and having real authority is $\tilde{b} \equiv b+\alpha u(w)$ for $u(w)<b$ and $\tilde{b} \equiv u(w)+\alpha b$ for $u(w) \geq b$ : When $u(w)<b$, the agent always picks his preferred decision; when there is congruence, the agent also receives wage $w$. The case $u(w) \geq b$ can be labeled "aligned incentives." The agent's monetary incentives are powerful enough that he forgoes his private benefit and always recommends the principal's preferred decision. Note that it is never optimal for the principal to set a wage just below $u^{-1}(b)$, because she can obtain congruent decision making by raising the wage slightly.

The reaction curves (5) and (6) under $P$-formal authority become

$$
(1-\alpha e) \tilde{B}=g_{P}^{\prime}(E)
$$

and

$$
(1-E) \tilde{b}=g_{A}^{\prime}(e) .
$$

The main conclusion of this section can be drawn from these two equations. A higher wage increases real authority for two reasons: First, by raising the agent's incentives, it makes it more likely that the agent will be able to recommend a project. Second, it reduces the principal's incentive to monitor and therefore the probability that the principal overrules the agent.

Let $\{E(w), e(w)\}$ denote the solution of $\{(18),(19)\}$. Then the derivative of the principal's profit with respect to $w$ is

$$
\frac{d u_{P}}{d w}=(1-E) \alpha(B-w) \frac{d e}{d w}-[E+(1-E) e \alpha] .
$$

The first term on the right-hand side of (20) corresponds to the increase in initiative. The second term reflects the increase in the wage bill. The optimal wage (when incentives are not aligned) is equal to zero if $\alpha$ is small, but should be positive in general. ${ }^{23}$

${ }^{23}$ The equilibrium may not be immune to the possibility of renegotiation. For suppose that the principal and the agent have ex ante agreed on a wage $w$ and that the agent has learned the payoffs but the principal has not. Suppose that $b>u(w)$. Suppose further that the agent's information is hard information. (It is equally straightforward to study the case of soft information.) In case of noncongruence, the principal must raise the wage to $w^{*}=u^{-1}(b)$ in order to get a profit. She will be willing to do so if $w^{*}<B$. While renegotiation occurs, the principal may not want to commit to wage $w^{*}$ ex ante, because she can get away with a lower wage when she herself is informed or when the projects are congruent. The analysis is otherwise qualitatively similar to that developed in the absence of renegotiation. 
Remark 1.-Dual top management approach.-Chandler (in "Executive Roundtable" [1993, pp. 54-58]) observes that at (generally deemed successful) General Electric during the 1980s, the managers of the "core" businesses-the long-established, mature businesses-received little planning or attention from the corporate office and were run instead through strict monetary incentives (budgets and budget-based bonuses). The corporate office, in contrast, was very involved in the high-tech businesses (aerospace, aircraft engines, and medical equipment), for which monetary incentives are harder to design (because of the uncertainty and the novelty of the products). Our argument that better performance measurement raises an agent's real authority offers a rationale for this so-called dual top management approach.

Remark 2.-Our analysis in this section also suggests that the transition from "U-form" to "M-form" in large U.S. companies such as Du Pont or General Motors is likely to have induced by itself a transfer in real authority toward division managers. Indeed, by creating autonomous "profit centers," the new M-form organizations could yield more precise information about each division head's performance because they avoided "moral hazard in teams" problems between product and functional divisions. It thus became easier to use monetary incentives or career concerns in order to foster the division head's initiative (see Aghion and Tirole [1995] for more on the link between M-forms and initiative).

\section{Multiple Principals}

Having multiple principals is generally believed to affect an agent's behavior. While providing a full treatment of this topic lies out of the scope of this paper (see Burkart, Gromb, and Panunzi [1994] for a number of interesting developments in the area of corporate finance), a short discussion already yields a number of useful observations. There are two dimensions to the deconcentration of ownership: returns and authority.

Splitting returns. - The benefit, provided that it is monetary, can be split among several principals. Consider, for instance, the case of $n$ equal partners (or "co-owners"), each entitled to receive $1 / n$ of the return of the project. We assume the same cost function for all principals. The set of principals as a whole is informed if any of them is. Because they all want to maximize profit, the allocation of authority among them is irrelevant. Each principal's and the agent's reaction curves are given by, respectively,

$$
(1-E)^{n-1}(1-e \alpha) \frac{B}{n}=g_{P}^{\prime}(E)
$$


and

$$
(1-E)^{n} b=g_{A}^{\prime}(e) .
$$

Spreading monetary benefits among several principals has two effects on initiative. First, it generates free riding and therefore reduces monitoring. This effect dominates when the principal's cost function is not too convex, as is the case, for instance, for a quadratic cost. ${ }^{24}$ In this case, an increase in the number of principals raises initiative and results in a loss of control. On the other hand, with a very convex cost function, the multiplication of monitors substantially improves the monitoring structure, which may reduce initiative. $^{25}$

Splitting authority.-Splitting authority among several principals obviously has no consequence if the principals' objectives are aligned as in the previous example. But authority is often split among principals with imperfectly aligned objectives (marketing and manufacturing divisions in a matrix organization, multiple ministries, chambers in Congress, partners in a joint venture, or creditors in a bankruptcy process). Who has real authority then hinges on the matrix of congruence parameters among principals and agent, as well as on the governance mechanism (e.g., each principal can have veto power, or there can be majority voting with or without the participation of the agent). Depending on these considerations, the agent's initiative may be enhanced or reduced by the split of authority. A conflict of interest among principals may increase the probability of veto by one of them. It may also raise each principal's incentive to become informed and not to rely on the other principals' recommendations. On the other hand, for more collegial decision processes, the agent may be able to "play" his multiple principals against each other and thereby get his way (see Davis and Lawrence [1977] for a description of such behaviors).

${ }^{24}$ To show this, rewrite $\left(5^{\prime}\right)$ and $\left(6^{\prime}\right)$ in terms of the probability $\mathscr{E}$ that the principals be informed: Let $E(\mathscr{E}, n)$ be defined by $(1-E)^{n}=1-\mathscr{E}$. The first-order conditions are then

$$
(1-\mathscr{E})(1-e \alpha) B=n[1-E(\mathscr{E}, n)] g_{P}^{\prime}(E(\mathscr{E}, n))
$$

and

$$
(1-\mathscr{E}) b=g_{A}^{\prime}(e) .
$$

In the $(\mathscr{E}, e)$ space, an increase in $n$ shifts only the principals' reaction curve, through a change in the right-hand side of ( $\left.5^{\prime \prime}\right)$. We leave it to the reader to check that, for a quadratic $g_{P}$ function, the right-hand side of $\left(5^{\prime \prime}\right)$ increases with $n$.

${ }^{25}$ This point is most easily demonstrated with the following functions: $g_{P}(E)=0$ for $E \leq E_{0},=\infty$ for $E>E_{0}$. Then the probability that the principals are informed, $\mathscr{E}$, is given by $1-\mathscr{E}=\left(1-E_{0}\right)^{n}$. 


\section{Reputation and Forbearance of Formal Authority}

As is usual, an alternative to contracting or authority allocation is reputation. In practice, superiors try to develop reputations for "not intervening too often" or for "intervening only when justified." For conciseness, we shall not develop a formal model of reputation building, but it is straightforward to do so along familiar lines. We can sketch the broad idea of "intervening only when justified." Suppose that the superior faces a sequence of agents. For each agent, the payoff structure is as described above except that with some probability a noncongruent project imposes a nonnegligible expected loss on the principal instead of yielding nonnegative expected profit. For incentive purposes, it may then be optimal for the superior to commit to overruling the agent only if the noncongruent project yields a negative profit, in that overruling in the other case is ex post optimal for the principal but reduces initiative too much to be worth it ( $A$-formal authority would be optimal in Sec. IVA). A patient superior facing enough subordinates may then develop a reputation for overruling agents only if the noncongruent project yields a negative profit. So, the superior uses her authority to overrule the subordinate "in important matters," but voluntarily relinquishes this authority (which is different from rubber-stamping) in matters that are less important to her. This behavior would not be credible in a one-shot situation, in which the superior would systematically overrule when informed.

\section{E. Urgency and Delegation}

It is sometimes observed that the need to adapt quickly to customer requirements has forced firms to decentralize decision making (see, e.g., the discussions of Wyman and Gordon and WalMart in "Executive Roundtable" [1993]). This subsection has two purposes: It offers some insights into how delegation might be affected by the urgency of the decision, and it illustrates the case in which the agent's and principal's investigations are sequential (rather than simultaneous). We shall formalize the urgency of the decision by the length of a product life cycle, but several alternative interpretations are possible. Suppose that the superior can investigate only once the project proposal has been made. Let $T$ denote the horizon, that is, the time elapsed between the proposal (date 0 ) and the date at which the product becomes obsolete. Abusing terminology, we shall let $T$ stand for the product life cycle. The project yields profit $B$ if the principal is informed at date $t$ ( $\alpha B$ if she is not) per unit of time between the starting date for production $t \geq 0$ and date $T$, at which time a 
superior substitute arrives on the market. It yields zero before date $t$.

The principal's decision problem consists in choosing a stopping time $S \in[0, T]$ at which to start production even if her investigations have not been successful by then. Waiting longer gives her more time for monitoring; that is, the probability that the principal learns the payoffs herself before some date $\tau, F(\tau)$, is increasing, with density $f(\tau)$. There are, however, decreasing returns in monitoring, so the hazard rate $f(\tau) /[1-F(\tau)]$ is decreasing. Let us assume that the agent's information is soft. (For the only time in this paper, it actually makes a difference whether the information is soft or hard.) For a given stopping rule $S$, the principal obtains flow profit $B$ between the date of learning $t$ and $T$ if she learns payoffs at $t<S$, and she has expected flow profit $\alpha B$ between $S$ and $T$ if she has not learned payoffs by date $S$ and thus rubber-stamps the agent's project at date $S$. The principal's utility, conditional on the agent's having proposed a project, is therefore ${ }^{26}$

$$
\hat{u}_{P}=B \int_{0}^{S}\left(\frac{e^{-r t}-e^{-r T}}{r}\right) f(t) d t+\alpha B[1-F(S)]\left(\frac{e^{-r S}-e^{-r T}}{r}\right),
$$

where $r$ is the principal's rate of time preference. This objective function is quasi-concave, and the optimal stopping time either is zero if

$$
\frac{\alpha}{1-\alpha} \geq \frac{f(0)}{1-F(0)} \frac{1-e^{-r T}}{r}
$$

(for $\alpha$ large enough, the principal rubber-stamps without even checking) or is given by the first-order condition

$$
\alpha=\frac{f(S)}{1-F(S)}(1-\alpha)\left[\frac{1-e^{-r(T-S)}}{r}\right] .
$$

The left-hand side of (21) is the marginal cost of delaying the introduction of the product (divided by $B$ ); its right-hand side is equal to the conditional density of discovering the payoffs times the value of overruling the agent's choice between $S$ and $T$ (divided by $B$ ). The optimal stopping time if strictly positive increases with $T(1>$ $\partial S / \partial T>0)$ and decreases with $\alpha(\partial S / \partial \alpha<0)$, as we would expect. Our main result is that for a short horizon, the principal conducts

${ }^{26}$ In this formulation, the principal's cost of investigating is simply forgone profit due to delayed introduction of the product. The sequential model can also be formulated with a more standard disutility of the principal's effort. 
a cursory investigation. That is, the principal is more likely to rubberstamp, the more urgent the decision.

Finally, we have been silent about the agent's behavior in that we have implicitly assumed that his search time (which could be random) was exogenously given. In general, this time could depend on the urgency of the decision due to altered incentives of the agent. Another interesting question (in a world of random time of acquisition of information by the agent) is whether the agent would ever want to delay a proposal. Delaying the proposal delays the date of adoption (recall that $\partial S / \partial T<1$ ) but also reduces the probability of being overruled (because $\partial S / \partial T>0$ ). Clearly, an agent with a congruent project would not want to delay the proposal, but an agent with a noncongruent project might. In this case, a late proposal could signal a noncongruent project and be given substantial attention by the principal (since $\partial S / \partial \alpha<0$ ). A formal treatment of this lies outside the scope of this paper.

\section{F. Testing the Determinants of Real Authority}

While we all have personal experience with some determinants of real authority, it is harder to come up with more systematic evidence. The key issue is, of course, the measurement of real authority. The analysis above suggests that organizational characteristics such as the span of control, the concentration of ownership, and the number of principals and supervising layers are directly relevant for measuring (or assessing) the real authority enjoyed by subordinates within a firm. In addition, one may use questionnaires, look ex post at the nature of the decisions (e.g., is the decision appealing to the project engineers who make a recommendation to the managers?) and whom they benefit, count the number of times the agents are overruled (although here one must correct for the self-censorship that occurs when one agent knows that his preferred project will not go through), or find out who gets courted in the organization (the holders of substantial real authority). Such approaches to measuring real authority require much more careful attention than can be given here.

Evidence about real authority can also be read indirectly, for instance from courts' assessment of the extent of real authority. Consider the issue of liability in a hierarchy that exerts a negative externality on a third party. The legal literature on "vicarious" liability rules reflects the view that in situations in which the principal has direct power of intervention (i.e., has formal authority) and the agent has limited ability to pay for damages, the principal should (also) be held responsible (see Shavell [1987, chap. 7] for a state- 
ment of the argument). However, the idea that liability rules (i.e., the extent to which the principal[s] must be held responsible for damages to third parties) should also accommodate organizational characteristics that affect real authority is becoming increasingly popular among legal specialists (see Strasser and Rodosevich [1993] for an extensive account of the courts' view in this respect). According to that view, directors, parent companies, or creditors should be held more liable if they are involved in a smaller number of activities or with a smaller number of agents (or subsidiaries). ${ }^{27}$

\section{Summary}

Let us summarize our main points. (a) In an organization, the delegation of formal authority to a subordinate will both facilitate the agent's participation in the organization and foster his incentive to acquire relevant information about the corresponding activities. On the other hand, delegation involves a costly loss of control for the principal. As a result of this overall trade-off, we found that formal authority is more likely to be delegated for decisions (or activities) that are relatively unimportant for the principal; for which the principal can trust the agent; that are important to the agent, either because private benefits are high or because the principal cannot refrain from hurting the agent; and that are sufficiently "innovative" that the principal has not accumulated substantial prior expertise or competency. (b) We have shown that centralization (the nondelegation of formal authority) may jeopardize communication by making the agent concerned about being overruled, although it can also favor communication when the agent trusts his superior. (c) Finally, we have identified factors that may increase a subordinate's real authority: large span of control, urgency, reputation for moderate interventionism, performance measurement, and multiple principals. There doubtless are other factors, the investigation of which we leave for future research.

This paper aims only at being a first step toward a more general theory of authority and its delegation. There are many desirable ex-

\footnotetext{
${ }^{27}$ Our analysis also suggests that liability rules that allocate much responsibility to principals in integrated structures may have undesirable consequences "ex ante" when we allow for an endogenous choice of the authority structure. Such liability rules may indeed induce excessive divestiture in situations in which coordination considerations would naturally favor the emergence of integrated structures. (Such phenomena appear to have occurred in the United States following the introduction of the new environmental liability rules [see Ringleb and Wiggins 1990].) There is thus a trade-off between making the owners or managers in integrated firms responsible and at the same time avoiding inefficiencies in the allocation of formal authority.
} 
tensions, such as allowing for multilayered hierarchies and studying the complex webs of authority relationships in organizations. The analysis of this and other exciting questions related to authority and its delegation must await future research.

\section{References}

Aghion, Philippe, and Tirole, Jean. "Formal and Real Authority in Organizations." Discussion Paper no. 37. Toulouse: Inst. d'Economie Industrielle, 1994.

- "Some Implications of Growth for Organizational Form and Ownership Structure." European Econ. Rev. 39 (April 1995): 440-55.

$\rightarrow$ Arrow, Kenneth J. "Vertical Integration and Communication." Bell J. Econ. 6 (Spring 1975): 173-83.

Burkart, Mike; Gromb, Denis; and Panunzi, Fausto. "Large Shareholders, Monitoring and Fiduciary Duty." Manuscript. London: London School Econ.; Cambridge: Massachusetts Inst. Tech., 1994.

Chandler, Alfred Dupont. Strategy and Structure: Chapters in the History of the Industrial Enterprise. Cambridge, Mass.: MIT Press, 1962.

Crémer, Jacques. "Arm's Length Relationships." Q.J.E. 110 (May 1995): 275-95.

Davis, Stanley M., and Lawrence, Paul R. Matrix. Reading, Mass.: AddisonWesley, 1977.

De Bijl, P. "Delegation of Responsibility in Organizations." Manuscript. Tilburg: Tilburg Univ., 1994.

- "Strategic Delegation of Responsibility in Competing Firms." Manuscript. Tilburg: Tilburg Univ., 1995.

"Executive Roundtable on Corporate Strategy in the '90s." Continental Bank. J. Appl. Corporate Finance, no. 6 (1993), pp. 42-60.

$\rightarrow$ Grossman, Sanford J., and Hart, Oliver D. "The Costs and Benefits of Ownership: A Theory of Vertical and Lateral Integration." J.P.E. 94 (August 1986): 691-719.

$\rightarrow$ Hart, Oliver D., and Moore, John. "Property Rights and the Nature of the Firm." J.P.E. 98 (December 1990): 1119-58.

Jennergren, L. Peter. "Decentralization in Organizations." In Handbook of Organizational Design, vol. 2, Remodeling Organizations and Their Environments, edited by Paul C. Nystrom and William H. Starbuck. Oxford: Oxford Univ. Press, 1981.

$\rightarrow$ Ringleb, Al H., and Wiggins, Steven N. "Liability and Large-Scale, LongTerm Hazards." J.P.E. 98 (June 1990): 574-95.

Riordan, Michael H. "What Is Vertical Integration?" In The Firm as a Nexus of Treaties, edited by Masahiko Aoki, Bo Gustafsson, and Oliver E. Williamson. London: Sage, 1990.

Rodriguez, Diego, and Vayanos, Dimitri. "Decentralization and the Management of Competition." Manuscript. Cambridge: Massachusetts Inst. Tech., 1993.

Rotemberg, Julio. "Power in Profit Maximizing Organizations." Manuscript. Cambridge: Massachusetts Inst. Tech., 1993.

- "Formal Authority vs. Power in Profit Maximizing Organizations." Manuscript. Cambridge: Massachusetts Inst. Tech., 1994. 
Schmidt, Klaus. "The Costs and Benefits of Privatization." Manuscript. Bonn: Univ. Bonn, 1991.

Shavell, Steven. Economic Analysis of Accident Law. Cambridge, Mass.: Harvard Univ. Press, 1987.

$\rightarrow$ Simon, Herbert A. "A Formal Theory of the Employment Relationship." Econometrica 19 (July 1951): 293-305.

Strasser, Kurt A., and Rodosevich, Denise. "Seeing the Forest for the Trees in CERCLA Liability." Yale J. Regulation 10 (Summer 1993): 493-560.

Tirole, Jean. "Incomplete Contracts: Where Do We Stand?" Walras-Bowley lecture presented at the North American summer meetings of the Econometric Society, Quebec, 1994.

Weber, Max. Economy and Society: An Outline of Interpretive Sociology. New York: Bedminster Press, 1968.

Williamson, Oliver E. Markets and Hierarchies: Analysis and Antitrust Implications. New York: Free Press, 1975.

The Economic Institutions of Capitalism: Firms, Markets, Relational Contracting. New York: Free Press, 1985. 